\title{
Comparison of 3D turbulence measurements using three staring wind lidars and a sonic anemometer
}

Mann, Jakob; Cariou, Jean-Pierre; Courtney, Michael; Parmentier, Remy; Mikkelsen, Torben; Wagner, Rozenn; Lindelöw, Per Jonas Petter; Sjöholm, Mikael; Enevoldsen, Karen

\section{Published in:}

Meteorologische Zeitschrift

Link to article, DOI:

$10.1127 / 0941-2948 / 2009 / 0370$

Publication date:

2009

Document Version

Publisher's PDF, also known as Version of record

Link back to DTU Orbit

Citation (APA):

Mann, J., Cariou, J-P., Courtney, M., Parmentier, R., Mikkelsen, T., Wagner, R., Lindelöw, P. J. P., Sjöholm, M., \& Enevoldsen, K. (2009). Comparison of 3D turbulence measurements using three staring wind lidars and a sonic anemometer. Meteorologische Zeitschrift, 18(2), 135-140. https://doi.org/10.1127/0941-2948/2009/0370

\section{General rights}

Copyright and moral rights for the publications made accessible in the public portal are retained by the authors and/or other copyright owners and it is a condition of accessing publications that users recognise and abide by the legal requirements associated with these rights.

- Users may download and print one copy of any publication from the public portal for the purpose of private study or research.

- You may not further distribute the material or use it for any profit-making activity or commercial gain

- You may freely distribute the URL identifying the publication in the public portal 


\title{
Comparison of 3D turbulence measurements using three staring wind lidars and a sonic anemometer
}

\author{
Jakob ManN $^{1 *}$, JeAn-Pierre Cariou ${ }^{2}$, Michael S. Courtney ${ }^{1}$, Rèmy Parmentier ${ }^{2}$,

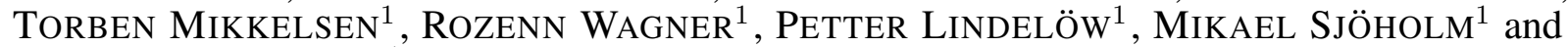 \\ KAREN ENEVOLDSEN ${ }^{1}$
}

${ }^{1}$ Wind Energy Department, Ris $\varnothing$ DTU, Roskilde, Denmark

${ }^{2}$ Leosphere, Paris, France

(Manuscript received September 30, 2008; in revised form November 19, 2008; accepted December 3, 2008)

\begin{abstract}
The goals are to compare lidar volume averaged wind measurement with point measurement reference sensors and to demonstrate the feasibility of performing 3D turbulence measurements with lidars. For that purpose three pulsed lidars were used in staring mode, placed so that their beams crossed close to a 3D sonic anemometer mounted at $78 \mathrm{~m}$ above the ground. The results show generally very good correlation between the lidar and the sonic times series, except that the variance of the velocity measured by the lidar is attenuated due to spatial filtering. The amount of attenuation can however be predicted theoretically by use of a spectral tensor model of the atmospheric surface-layer turbulence.
\end{abstract}

\section{Zusammenfassung}

Das Ziel ist es, volumengemittelte LiDAR-Windmessungen mit Punktmessungen von Referenzsensoren $\mathrm{zu}$ vergleichen sowie die Möglichkeit aufzuzeigen, 3D-Turbulenzmessungen mit LiDAR-Geräten durchzuführen. $\mathrm{Zu}$ diesem Zweck wurden drei gepulste LiDAR-Systeme mit fixer Blickrichtung so aufgestellt, dass ihre Strahlen nahe eines 3D-Ultraschall-Anemometers kreuzten, welches $78 \mathrm{~m}$ über Grund befestigt war. Die Ergebnisse zeigen im Allgemeinen sehr gute Korrelationen zwischen den Zeitreihen der LiDAR- und Ultraschall-Anemometer, allerdings wird die Streuung der vom LiDAR gemessenen Geschwindigkeit durch räumliches Filtern abgeschwächt. Der Grad der Abschwächung kann jedoch mittels eines spektralen Tensormodells, das die Turbulenz in der atmosphärischen Bodenschicht beschreibt, theoretisch vorausberechnet werden.

\section{Introduction}

For wind energy research and also for micro-meteorology one wants to be able to measure turbulence, not just the statistics, but time series of the fluctuating threedimensional velocity. We have made such measurements with three pulsed lidars pointing towards the same position in space and investigated how well the lidar turbulence measurements compare with those from a collocated sonic anemometer. COLLIER et al. (2005) did similar investigations with two lidars, but this is the first time three lidars have been combined to measure atmospheric three-dimensional turbulence. The experiment can be viewed as a first step towards realizing a 3D steerable lidar system capable of scanning the flow around a wind turbine (MIKKELSEN et al., 2008).

\section{The experiment}

Four pulsed coherent Doppler lidars from Leosphere (WindCubes) were used in the experiment. Three of

\footnotetext{
${ }^{*}$ Corresponding author: Jakob Mann, Wind Energy Department, Ris $\varnothing$ DTU, Frederiksborgsvej 399, 4000 Roskilde, Denmark, e-mail: jakob.mann@risoe.dk
}

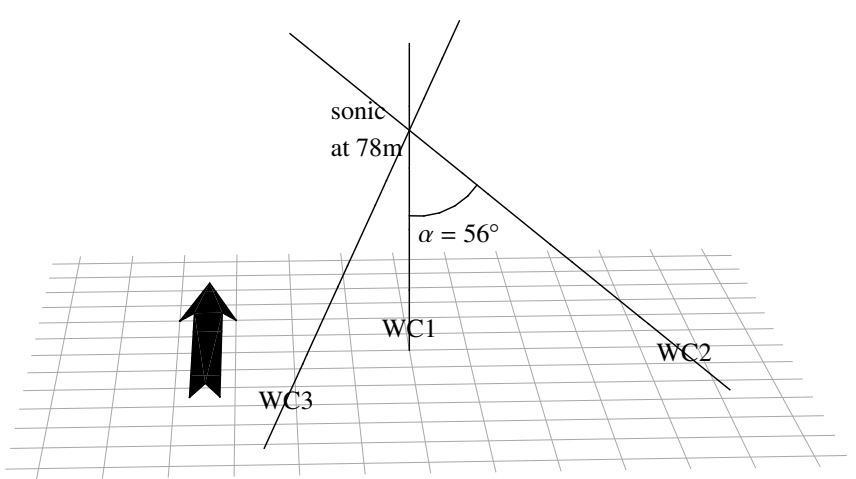

Figure 1: Sketch of the experiment as seen from the south. The arrow points towards the north.

them were staring towards a Metek sonic anemometer (USA-1 Scientific) $78 \mathrm{~m}$ above the ground. The first, WC1, pointed vertically, the two others, WC2 and WC3, pointed $\alpha=56^{\circ}$ away from vertical. The angle WC3 $\mathrm{WC} 1-\mathrm{WC} 2$ was $90^{\circ}$. In the horizontal direction WC2 pointed $26^{\circ}$ north of west, while WC 3 pointed $26^{\circ}$ east of north, see Figure 1.

The intention with the fourth WindCube, which was scanning conically, is to compare the computed time se- 

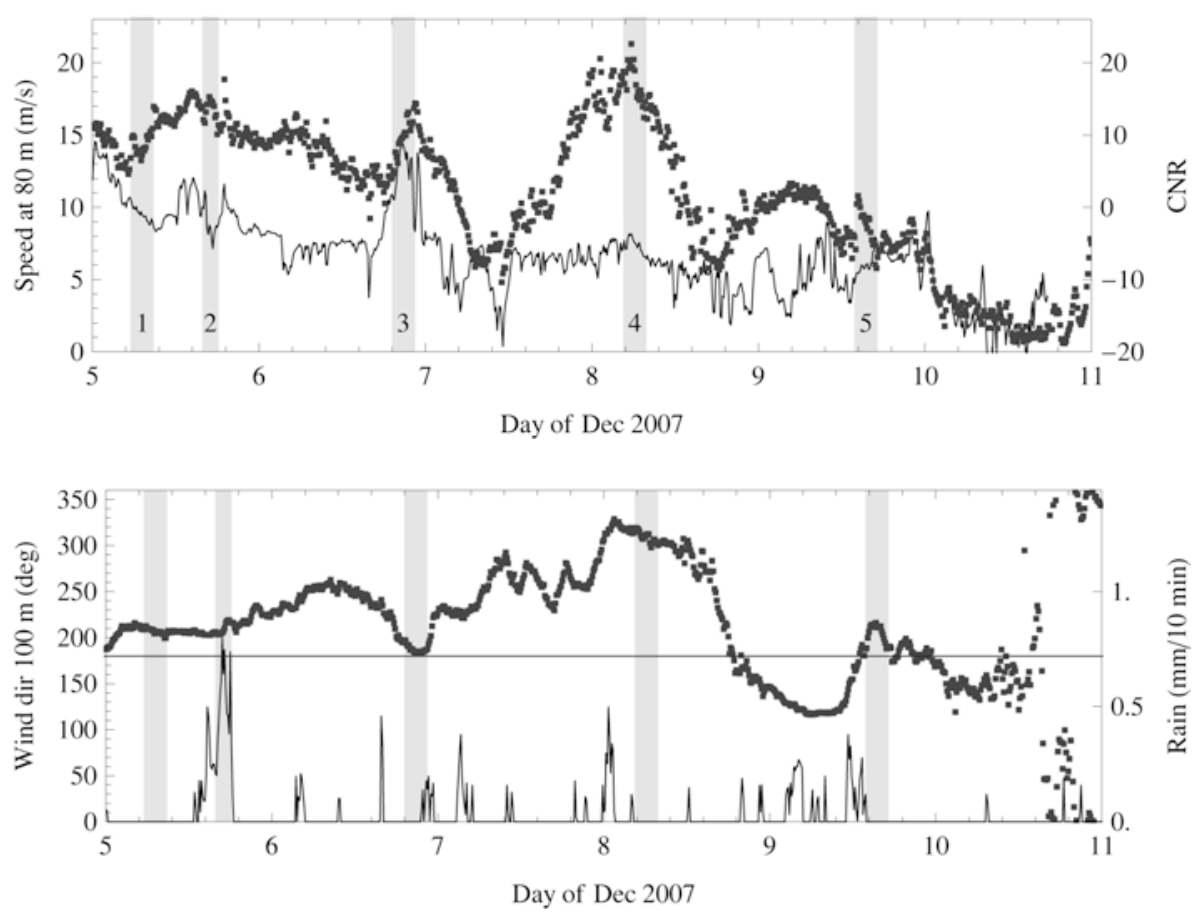

Figure 2: Top: The wind speed measured by a cup anemometer (dots) and carrier-to-noise-ration CNR in dB (curve). Bottom: Wind direction measured by a vane (dots) and rain (curve) during the experimental campaign. The five detailed investigation periods shown in gray are listed in Table 1 . Measurements with directions less than $180^{\circ}$ are not used in the analysis because of wakes from the mast and wind turbines.

Table 1: Turbulence characteristics of the five periods used for spectral analysis. The run start and end are names of the ten minutes periods starting and ending the run and both are included. $U$ is the mean wind speed, dir. the direction, $\sigma / U$ the normalized standard deviations of the three velocity components, $\alpha$ the Kolmogorov constant, $\varepsilon$ the energy dissipation, $L$ a turbulence length scale and $\Gamma$ a parameter describing the anisotropy of the turbulence.

\begin{tabular}{ccccccccccc}
\hline Period & Run starts & Run ends & $U[\mathrm{~m} / \mathrm{s}]$ & dir. $\left[{ }^{\circ}\right]$ & $\frac{\sigma_{u}}{U}[\%]$ & $\frac{\sigma_{v}}{U}[\%]$ & $\frac{\sigma_{w}}{U}[\%]$ & $\frac{\alpha \varepsilon^{2 / 3} z^{2 / 3}}{10^{-3} U^{2}}$ & $L[\mathrm{~m}]$ & $\Gamma$ \\
\hline 1 & 200712050530 & 200712050850 & 14.5 & 207 & 7.0 & 7.9 & 3.1 & 5.4 & 14 & 1.9 \\
2 & 200712051550 & 200712051810 & 16.8 & 213 & 7.7 & 11.6 & 3.9 & 6.3 & 18 & 2.4 \\
3 & 200712061910 & 200712062230 & 14.9 & 190 & 12.2 & 7.9 & 4.5 & 5.8 & 32 & 2.7 \\
4 & 200712080430 & 200712080750 & 19.0 & 314 & 9.3 & 12.6 & 4.2 & 3.7 & 42 & 3.9 \\
5 & 200712091350 & 200712091710 & 8.6 & 204 & 18.8 & 19.4 & 4.0 & 5.4 & 27 & 2.8 \\
\hline
\end{tabular}

ries of wind vectors assuming horizontal homogeneity with the real wind vector measured by the three staring lidars or the sonic anemometer. That analysis will be reported elsewhere.

The experiment took place at the Test Station for Large Wind Turbines at Høvsøre in Western Denmark, operated by Risø DTU. The surrounding terrain is flat and agricultural, and the North Sea is $1.5 \mathrm{~km}$ due west. More information on the test site and the lidar may be found elsewhere (SMITH et al., 2006; COURTNEY et al., 2008). The experiment ran for almost a week in December 2007 and recorded 10 minute average wind speeds up to $21 \mathrm{~m} / \mathrm{s}$ as seen from Figure 2. The data shown in this Figure are from a well equipped meteorological mast a few hundred meters to the south of the position of the lidars. The carrier-to-noise-ratio $C N R$ of the lidars varies more than a factor of one hundred during the experiment as a consequence of varying aerosol content in the atmosphere and thereby backscatter. Frequent light showers are scattered throughout the campaign as seen from the rain gauge in Figure 2.

For detailed comparison of the lidar and sonic winds, we select five periods characterized by varying levels of winds, turbulence, rain and backscatter. The five periods are shown in gray in Figure 2 and turbulence characteristics are shown in Table 1 . The turbulence intensities of the three wind components $u$ (in the mean wind direction), $v$ (horizontal perpendicular to the mean wind), and $w$ (vertical) are calculated from all data in the periods without de-trending. The last three columns are fitting 


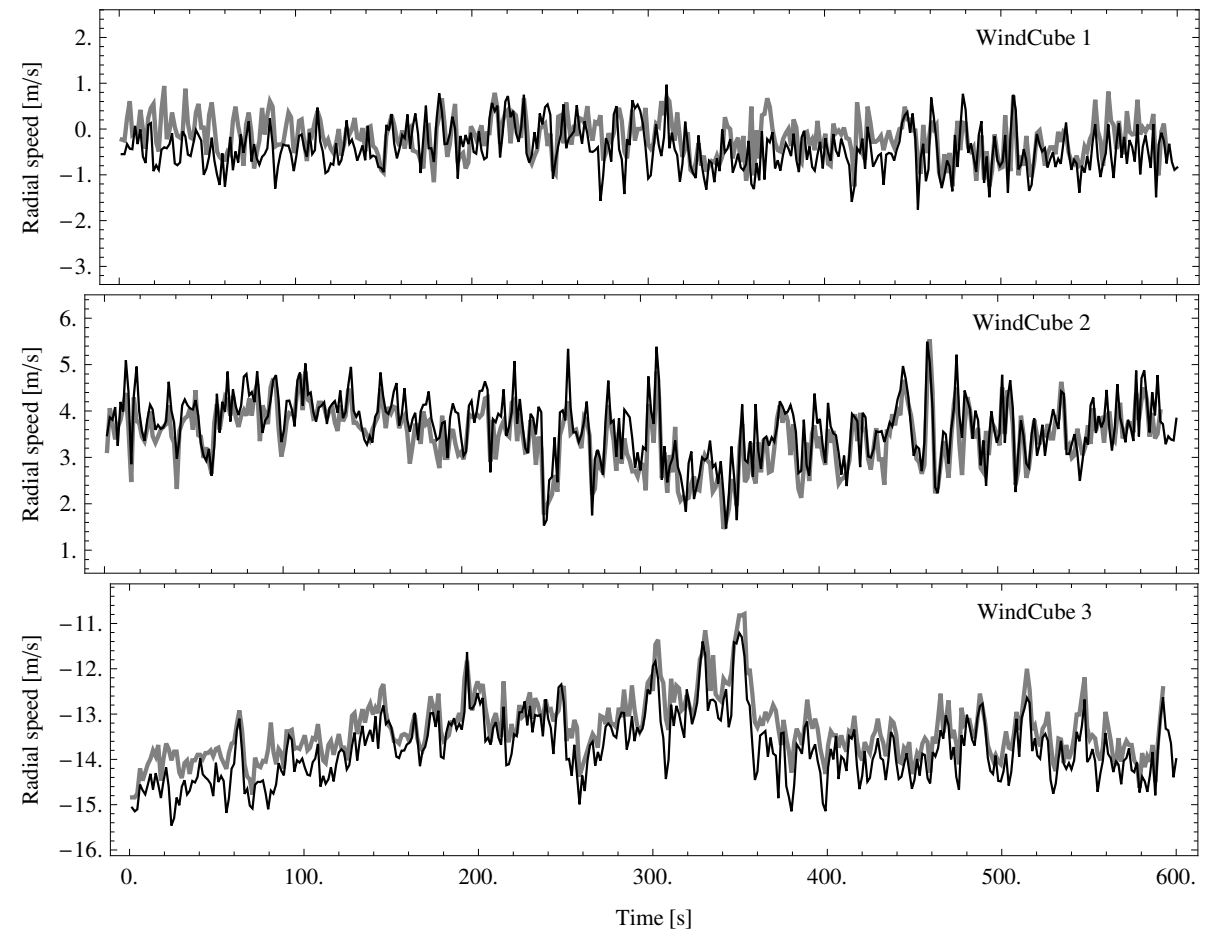

Figure 3: A ten minute period of wind data centered in Period 2. The thin, black curve is the three-dimensional sonic data projected onto the direction of the beam of the WindCube while the data from the lidar are shown in a thicker gray curve.

parameters to a turbulence model to be explained later.

In Figure 3 and 4 ten minutes time series of wind speed from the three WindCubes are shown together with sonic measurements from Period 2 and 4 . If $\boldsymbol{n}$ is a unit vector in the direction of a lidar beam (by convention positive towards the lidar) and $\boldsymbol{u}$ is the wind vector measured by the sonic, then the quantity shown for the sonic is $\boldsymbol{n} \cdot \boldsymbol{u}$. The sonic speeds have been block averaged over $1.5 \mathrm{~s}$ corresponding to the sampling rate of the lidar. Each wind speed determination by the lidar is based on Doppler spectra averaged over $0.5 \mathrm{~s}$. The lidars have a bias, probably due to pulse chirp, which has been subtracted. The bias has been determined by an independent experiment to be $1.1,0.0$, and $-0.1 \mathrm{~m} / \mathrm{s}$ for the three lidars.

It is not expected that the fluctuating time series from the sonic and the lidars should be identical because the lidar averages over a $30 \mathrm{~m}$ long volume in space, while, apart from the time averaging, the sonic essentially provides a point measurement. Figure 3 and 4 represent the extremes of how well the lidar follows the sonic signals. In Figure 3 we observe some resemblance between the time series, whereas in Figure 4 the match is almost perfect except from a slight offset for the vertically pointing WC1. The sonic seems to have $\langle w\rangle \neq 0$ which should not be expected from the rather flat site.

\section{Detailed comparison of 3D turbulence measurements}

We would now like to understand in more detail the limitations in the lidar turbulence measurements compared to the sonic, which is the preferred instrument for atmospheric turbulence. We assume that the wind speed measured by the lidar is

$$
v(\boldsymbol{x})=\int_{-\infty}^{\infty} \varphi(s) \boldsymbol{n} \cdot \boldsymbol{u}(s \boldsymbol{n}+\boldsymbol{x}) d s,
$$

where $\boldsymbol{n}$ is a unit vector in the direction of the laser beam, $\boldsymbol{u}(\boldsymbol{x})$ is the velocity field. The center of the lidar measuring volume is $\boldsymbol{x}$. This particular expression assumes the backscatter to be homogeneously distributed. We suppress the time dependence since we assume Taylor's frozen turbulence hypothesis to be valid (PANOFSKY and DUTTON, 1984). The weighting function $\varphi$ is normalized to unit integral and several suggestions of its shape are investigated. The most commonly accepted is

$$
\varphi(s)=\left\{\begin{array}{cc}
\frac{l-|s|}{l^{2}} & \text { for }|s|<l \\
0 & \text { elsewhere }
\end{array}\right.
$$

where $l$ is the half length of an ideally rectangular light pulse leaving the lidar assuming a matching time windowing $(=2 l / c)$. The expression is valid if the Doppler frequency is determined as the first moment of the signal spectrum with the background subtracted appropriately (BANAKH and WERNER, 2005). However, the Doppler 


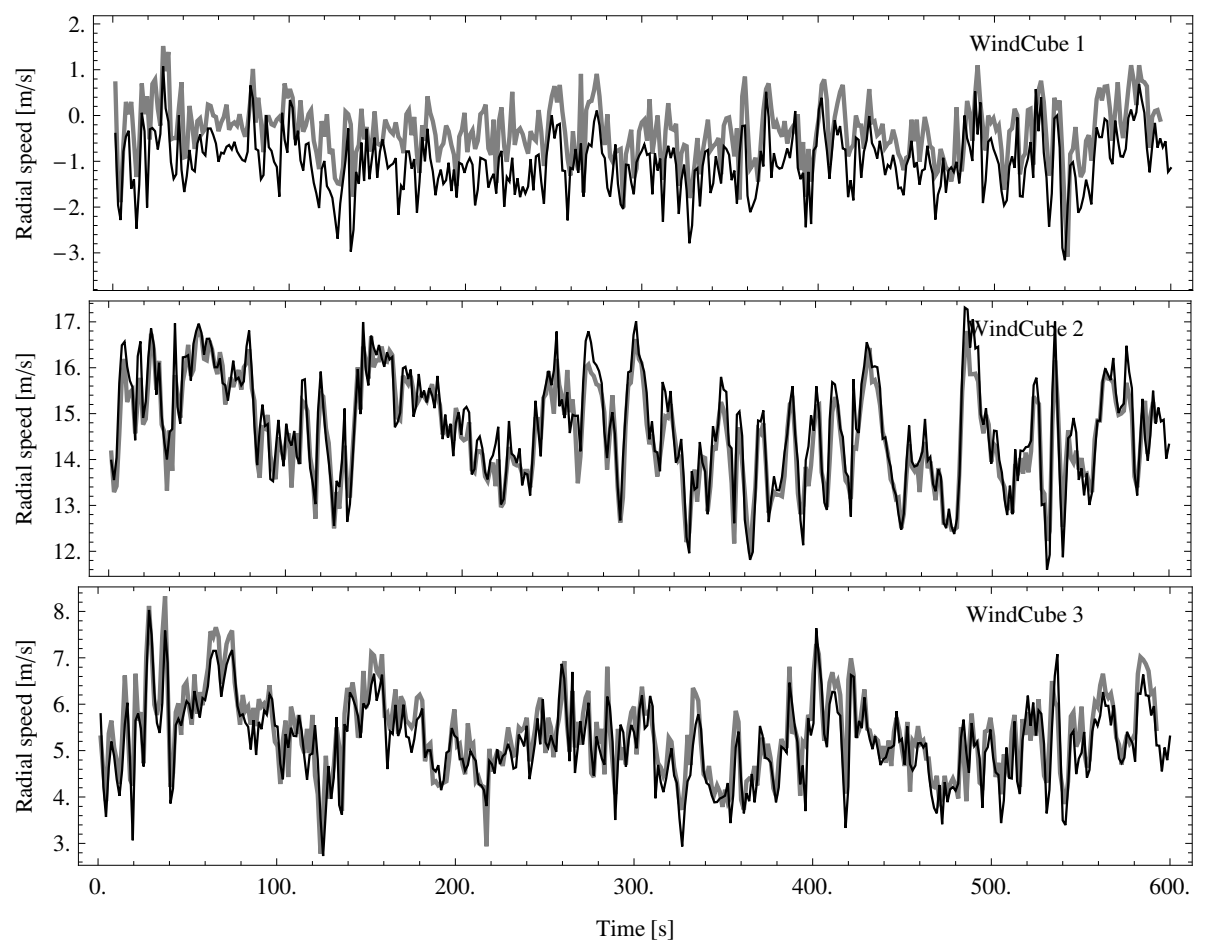

Figure 4: A ten minute period of wind data centered in Period 4. See Figure 3.

shift is not always determined in this way and there have been other suggestions. One of these, which is thought to have relevance for the way the radial velocity is determined from the WindCube lidar, is (LINDELÖw, 2008)

$$
\varphi(s)=\left\{\begin{array}{cl}
\frac{3(l-|s|)^{2}}{2 l^{3}} & \text { for }|s|<l \\
0 & \text { elsewhere }
\end{array} .\right.
$$

We ignore any effect of focusing of the pulsed lidar, which in a more detailed analysis should be taken into account (LINDELÖW, 2008). In the case of the WindCube $l=30 \mathrm{~m}$. The Fourier transforms of these weighting functions, which we are going to use later, are

$$
\varphi(k)=\left\{\begin{array}{cc}
\operatorname{sinc}^{2}(k l / 2) & \text { based on (3.2) } \\
\frac{6}{k^{2} l^{2}}(1-\operatorname{sinc}(k l)) & \text { based on (3.3) }
\end{array},\right.
$$

where $\operatorname{sinc}(x) \equiv(\sin x) / x$.

We are now interested in the spectrum of $v$ and how it is influenced by the averaging in (3.1). It is clear that if the filter length $l$ is sufficiently small the velocity measured by lidar would simply be $\boldsymbol{n} \cdot \boldsymbol{u}$ and the spectrum could be expressed as a combination of the unfiltered one-point spectra of the velocity components.

The correlation function of $v$ is

$$
\begin{aligned}
R_{v}\left(x_{1}\right)= & \left\langle v(\boldsymbol{x}) v\left(\boldsymbol{x}+x_{1} \boldsymbol{e}_{1}\right)\right\rangle \\
= & \iint \varphi(s) \varphi\left(s^{\prime}\right) n_{i} n_{j} \times \\
& \left\langle u_{i}(s \boldsymbol{n}+\boldsymbol{x}) u_{j}\left(s^{\prime} \boldsymbol{n}+\boldsymbol{x}+x_{1} \boldsymbol{e}_{1}\right)\right\rangle d s d s^{\prime}
\end{aligned}
$$

$$
\begin{aligned}
= & n_{i} n_{j} \iint \varphi(s) \varphi\left(s^{\prime}\right) \times \\
& R_{i j}\left(\left(s^{\prime}-s\right) \boldsymbol{n}+x_{1} \boldsymbol{e}_{1}\right) d s d s^{\prime}
\end{aligned}
$$

where $R_{i j}$ is the correlation tensor of the velocity field (POPE, 2000) and where summation over repeated indices is assumed. We have also assumed, in order to use the three-dimensional correlations tensor, that the turbulence is homogeneous, not only in the flow direction, but also in the two directions perpendicular to that. This assumption is well met in the horizontal direction, but less so in the vertical (MANN, 1994). The spectrum of $v$ is now obtained by Fourier transforming (3.5) and can be expressed as

$$
\begin{aligned}
F_{v}\left(k_{1}\right)= & \frac{1}{2 \pi} \int\left\langle v(\boldsymbol{x}) v\left(\boldsymbol{x}+x_{1} \boldsymbol{e}_{1}\right)\right\rangle \mathrm{e}^{-\mathrm{i} k_{1} x_{1}} d x_{1} \\
= & n_{i} n_{j} \iint \varphi(s) \varphi\left(s^{\prime}\right) \iint \Phi_{i j}(\boldsymbol{k}) \times \\
& \exp \left(\mathrm{i} \boldsymbol{k} \cdot \boldsymbol{n}\left(s^{\prime}-s\right)\right) d k_{2} d k_{3} d s d s^{\prime} \\
= & n_{i} n_{j} \iint|\varphi(\boldsymbol{k} \cdot \boldsymbol{n})|^{2} \Phi_{i j}(\boldsymbol{k}) d k_{2} d k_{3}
\end{aligned}
$$

The steps in this derivation includes changing the order of integration of $k$ and $s$ and then splitting the double integral over $s$ and $s^{\prime}$ into a product of integrals, which essentially are Fourier transforms of $\varphi$.

It is important to point out that it is not enough to know the second order turbulence statistics at the height of the sonic anemometer, in order to calculate the lidar spectra. We need three-dimensional, spatial statistics, or, in other 

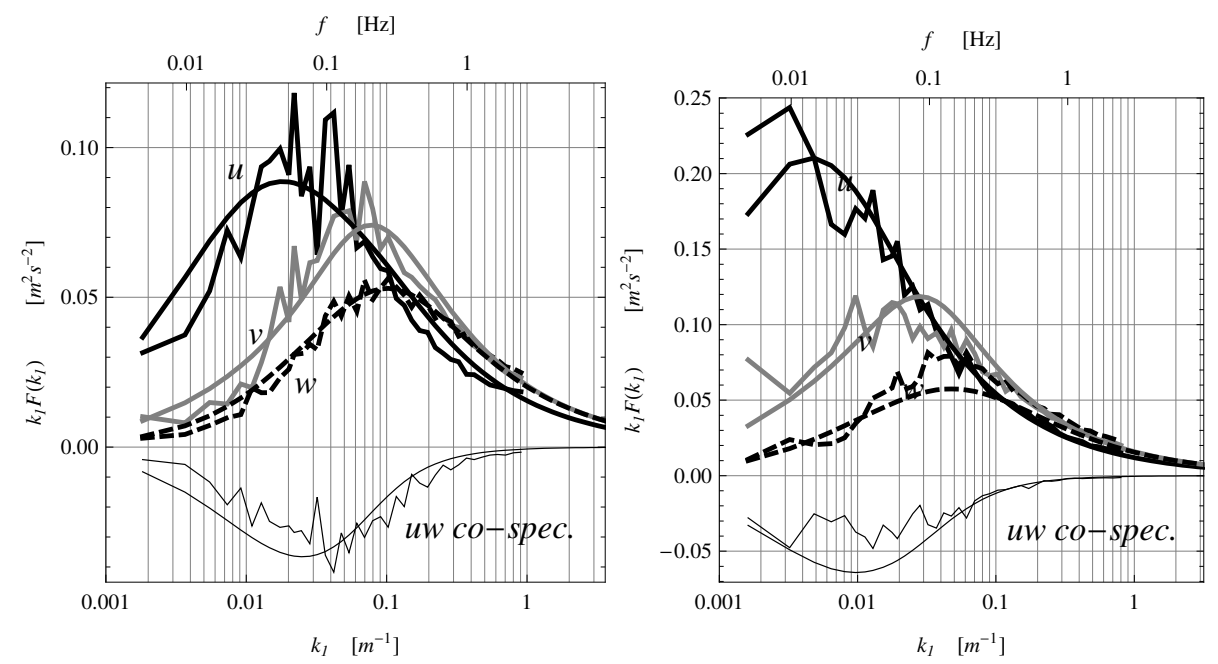

Figure 5: Measured and modeled spectra for the time periods 2 and 4 (see Figure 2) showing the large difference in turbulence length scale. The $u$-spectrum is black, $v$ gray and $w$ dashed. The co-spectrum of $u$ and $w$ is shown in black below zero. Smooth curves are model spectra, the ragged curves measurements.
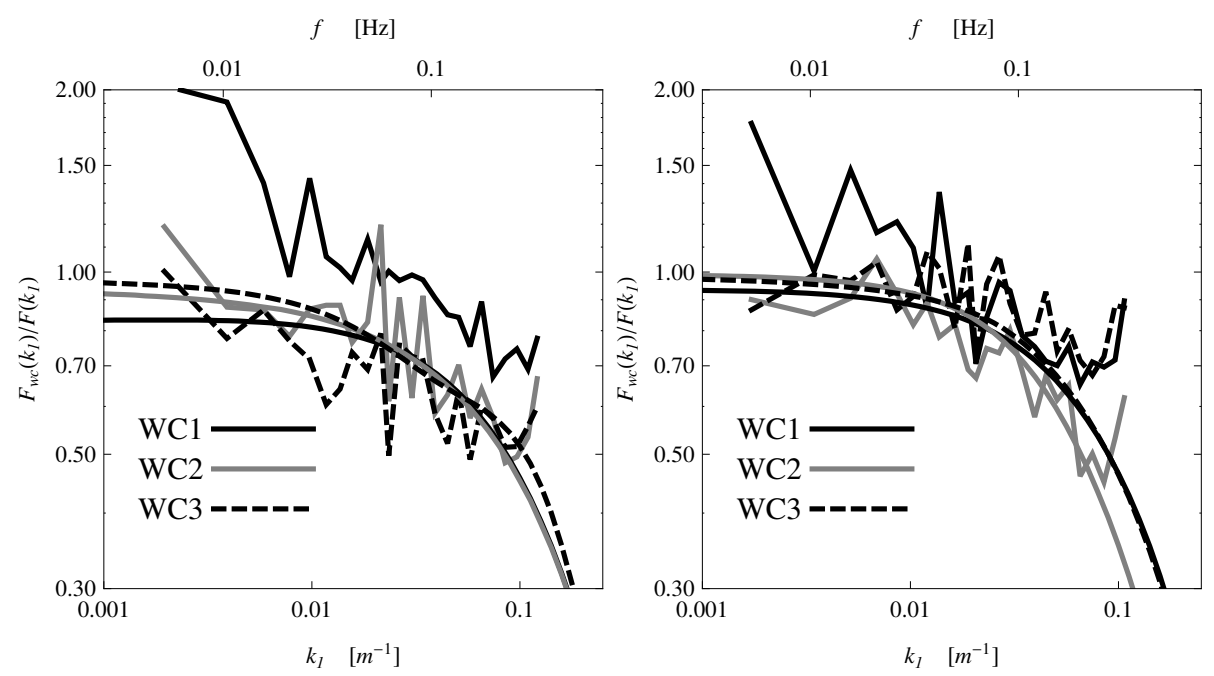

Figure 6: The ratio of lidar spectra and sonic spectra for period 2 (left) and 4 (right) and the corresponding theoretical predictions (smooth curves).

words, the spectral tensor $\Phi_{i j}(\boldsymbol{k})$, as seen from (3.6). It is difficult to measure directly, but fortunately, the spectral tensor model by MANN (1994) allows us to estimate $\Phi(\boldsymbol{k})$ through measurements from a sonic. This is done by fitting three parameters $\alpha \varepsilon^{2 / 3}, L$ and $\Gamma$ to the three one-dimensional spectra measured by the sonic. Here $\alpha$ is the spectral Kolmogorov constant (POPE, 2000), $\varepsilon$ is the turbulent energy dissipation, $L$ is a length scale proportional to the size of the energy containing eddies in the turbulence, and $\Gamma$ is a parameter describing the degree of anisotropy of the turbulence (MANN, 1994). For the time periods 2 and 4 the fitted and measured spectra are shown in Figure 5, while parameters for all periods are in Table 1. The model by MANN (1994) is derived for neutral flow over homogeneous terrain. The atmo- spheric stability is, despite the strong winds, not exactly neutral and the terrain is, because of the nearby shoreline, not completely homogeneous. Had the flow been neutral and homogeneous, the length scales (and other parameters) in table 1 should have been identical. Nevertheless, we use the model to fit the one-dimensional turbulence data and to extrapolate to the three-dimensional structure.

-With these values we are now able to evaluate (3.6) and estimate theoretically the ratio between the velocity spectrum measured by the lidar and the sonic. The ratio of the spectra from both instruments are shown in Figure 6 together with the theoretical expectations, where we have used the triangle window function (3.2). In addition to (3.6) the theoretical ratios have been multiplied 
with $\operatorname{sinc}^{2}\left(k_{1} l / 2\right)$ where $l=t_{a} U$ with $t_{a}=0.5 \mathrm{~s}$, because the WindCube spectra are obtained by averaging over half a second.

The theoretical predictions for the three lidars differ because they are oriented differently. The predictions for period 2 (left plot in Figure 6) for low wavenumbers are slightly lower than the corresponding predictions for period 4, especially for the vertically pointing $\mathrm{WC} 1$. However, the ratio of WindCube 1 and the vertical component spectra especially at low frequencies is significantly larger than one. At low frequencies the spectral energy content of the vertical component is much lower than that of the two horizontal, as seen from Figure 5. Therefore, if the lidar WindCube 1 were not pointing completely vertical, the spectrum could be influenced by the horizontal component at these low frequencies. Plotting the mean vertical wind speed from $\mathrm{WC} 1$ as a function of direction shows that the instrument is not deviating significantly from pointing vertically, and we were forced to look at other explanations. After the experiment we ran all WindCubes in scanning mode side by side. Also here WC1 showed larger radial wind speed variance compared to the others. The source of the noise is most likely due to a pulse rebound into the acoustooptic modulator. The manufacturer Leosphere has after the experiment eliminated the noise by reducing slightly the laser output power.

Apart from the problem with WC1 the spectrum ratios seem to follow quite well the theoretical expectations. We have also calculated the theoretical spectrum ratios based on the alternative window function (3.3). The statistics are, however, not good enough to distinguish between the filter functions (3.2) and (3.3). Close to the Nyquist frequency of the lidar measurements, the spectra seem to rise, probably due to noise.

Period 2 was chosen to see the influence of rain on the turbulence measurements, but we were not able to see any significant influence. Also the carrier to noise ratio $C N R$ seems to have little effect. The reason for the very different appearance of the time series from period 2 and 4 (see Figures 3 and 4) is that in period 2 the turbulence length scale is shorter than the lidar's spatial filter length. Therefore the weighted velocity measured by the lidar (3.1) can be quite different from the point measurement of the sonic. Conversely, in period 4 the turbulent eddies are so large that they almost engulf the entire lidar sampling volume and give a relatively even velocity distribution within that.

\section{Conclusion}

For the first time, three lidars have been run concurrently to measure the fluctuating atmospheric three- dimensional velocity at one point. The times series measured by lidars and the sonic anemometer agree very well down to time scales of the order of two seconds. However, the agreement deteriorates as the turbulence length scale decreases. The variance of the velocity measured by the lidar is attenuated due to spatial filtering, and the amount of attenuation can, in general, be predicted theoretically by use of a spectral tensor model. The vertically pointing lidar WC1 does occasionally show unexpectedly large spectral densities, due to a malfunction in the instrument. We have tested two slightly different forms of the spatial weighting function. However, the data do not permit us to distinguish the two different proposals.

\section{Acknowledgments}

We would like to thank technicians at the test station at Høvsøre, Bjarne SøNDERSKOV and Anders Ramsing VESTERGAARD, for their practical help during the experiment.

\section{References}

BANAKH, V.A., C. WERner, 2005: Computer simulation of coherent doppler lidar measurement of wind velocity and retrieval of turbulent wind statistics. - Opt. Eng. 44, 071205.

Collier, C.G., F. Davies, K.E. Bozier, A.R. Holt, D. R. Middleton, G. N. Pearson, S. Siemen, D. V. Willetts, G. J. G. Upton, R. Young, 2005: DualDoppler lidar measurements for improving dispersion models. - Bull. Amer. Meteor. Soc. 86, 825.

Courtney, M., R. WAgner, P. Lindelöw, 2008: Testing and comparison of lidars for profile and turbulence measurements in wind energy. - IOP Conference Series: Earth and Environmental Science 1, 012021, 14 pp.

LINDELÖW, P., 2008: Fiber Based Coherent Lidars for Remote Wind Sensing. - Ph.D. thesis, Danish Technical University.

MANN, J., 1994: The spatial structure of neutral atmospheric surface-layer turbulence. - J. Fluid Mech. 273, 141-168.

Mikkelsen, T., J. MAnN, M. Courtney, M. SuÖholm, 2008: Windscanner: 3-d wind and turbulence measurements from three steerable doppler lidars. - IOP Conference Series: Earth and Environmental Science 1, 012018, 9 pp.

PAnOfsky, H.A., J.A. DutTon, 1984: Atmospheric Turbulence. - John Wiley \& Sons, New York.

Pope, S. B., 2000: Turbulent Flows. - Cambridge University Press.

Smith, D.A., M. Harris, A.S. CofFey, T. MikKelsen, H.E. Jørgensen, J. MAnN, R. DAnielian, 2006: Wind lidar evaluation at the Danish wind test site Høvsøre. Wind Energy 9, 87-93. 